\title{
Development of Spinitectus inermis (Nematoda: Cystidicolidae), a parasite of eel, Anguilla anguilla, in Europe
}

\author{
Aurélia Saraiva $^{1}$, František Moravec $^{2}$, Anabela Pereira $^{1}$ and Cristina Cruz $^{1}$ \\ ${ }^{1}$ Departamento de Zoologia e Antropologia, Faculdade de Ciências, Universidade do Porto, Praça Gomes Teixeira, 4099-002 \\ Porto, Portugal; \\ ${ }^{2}$ Institute of Parasitology, Academy of Sciences of the Czech Republic, Branišovská 31, 37005 České Budějovice, Czech \\ Republic
}

Key words: Nematoda, Spinitectus inermis, eel, Anguilla anguilla, Ephemeroptera, intermediate host, Portugal, Czech Republic

\begin{abstract}
The development of the nematode Spinitectus inermis (Zeder, 1800), a parasite of the stomach of eels, Anguilla anguilla (L.) in Europe, was experimentally studied. Mayfly nymphs Caenis macrura, Ecdyonurus dispar, Heptagenia sulphurea, Potamanthus luteus and Seratella ignita from Portugal and the Czech Republic were found to serve as experimental intermediate hosts. After ingestion of the nematode eggs by the mayfly nymphs, the toothed first-stage larvae were released and penetrated into the body cavity of the intermediate host. There they moulted twice (on day 4 and 6 post infection [p.i.] at water temperatures of $20-25^{\circ} \mathrm{C}$ ), attaining the third infective stage. The definitive host, A. anguilla, undoubtedly acquires infection by feeding on mayfly nymphs harbouring infective-stage larvae. In an experimentally infected eel, the fourth-stage larva undergoing the third moult was observed 28 days p.i. at water temperature of $20^{\circ} \mathrm{C}$. The larval stages, including moulting forms, are described and illustrated. The prepatent period of $S$. inermis is estimated to be about two months.
\end{abstract}

The genus Spinitectus Fourment, 1883 includes numerous species of medium-sized nematodes parasitic in the digestive tract of freshwater and marine fishes, some amphibians, and one species was described from a mammal (Boomker 1993). The life cycles and transmission of these parasites are mostly unknown. There are only four species in which the development has been studied experimentally.

Gustafson (1939) was the first to show experimentally that Spinitectus gracilis Ward et Magath, 1917, a parasite of North American freshwater fishes, could develop in three genera of mayfly nymphs, but no details or figures were provided. Yamaguti and Nishimura (1944) and Johnson (1966) recorded Spinitectus larvae from freshwater shrimps (Crustacea) in Japan and India and speculated that they might be Spinitectus ranae Morishita, 1926 (a parasite of amphibians) and Spinitectus armatus Ali, 1956 (a parasite of catfishes), respectively. Otsuru et al. (1974) and Hasegawa (1978) described Spinitectus sp. larvae from freshwater shrimps in Japan; feeding of these larvae to experimental amphibians, carried out by Hasegawa and Otsuru (1977), provided adult S. ranae. A larva presumed to belong to the closely related genus Neospinitectus Kalyankar, 1971 was reported from a freshwater shrimp in India by Ali (1980).

Third-stage larvae, identified as S. gracilis, were recorded from naturally infected mayfly nymphs Hexagenia sp. in Missouri, USA by Keppner (1975). Jilek and Crites (1981) found various aquatic insect larvae belonging to different orders (Ephemeroptera, Plecoptera, Diptera) naturally infected with third-stage larvae of $S$. gracilis and S. carolini Holl, 1928, both fish parasites, in Ohio, USA.

Of many described species of Spinitectus, the larval development in the intermediate host has so far been experimentally studied only in three species parasitising North American fishes. Keppner (1975) first documented the development of larvae of $S$. micracanthus Christian, 1972, a parasite of the bluegill (Lepomis macrochirus Rafinesque), both in the mayfly intermediate host (Hexagenia sp.) and the fish definitive host, whereas Jilek and Crites (1980, 1981, 1982a, b) studied the same in S. carolini and S. gracilis, using various insects (Ephemeroptera, Odonata, Plecoptera, Collembola) as experimental intermediate hosts.

In Europe, two species of Spinitectus occur in freshwater fishes: Spinitectus inermis (Zeder, 1800), a specific parasite of the European eel, Anguilla anguilla (L.), and S. gordoni Cordero del Campillo et Alvarez Pellitero, 1976, a parasite of salmonids, Oncorhynchus mykiss (Walbaum) and Salmo trutta m. fario L. (Moravec 1994). Nothing is known about the life cycles of these species.

Spinitectus inermis is an abundant parasite of eels in the Sousa River, a tributary of the Douro River, in northern Portugal, which enabled the experimental study of its life cycle. The present paper describes the results obtained from experimental infections of the intermediate and definitive hosts of $S$. inermis and 
provides the first description of fourth-stage larvae of this parasite from naturally infected eels.

\section{MATERIALS AND METHODS}

Gravid females of $S$. inermis were obtained from the stomach of A. anguilla collected by electrofishing from the Sousa River, a tributary of the Douro River, northern Portugal in the period from November 1998 to November 2000. Mayfly nymphs (Ephemeroptera) used in experiments originated either from the same locality (Sousa R.) in Portugal or from the Malše River near České Budějovice, South Bohemia, in the Czech Republic.

The nematodes obtained from fish were washed in physiological saline. In Portugal, S. inermis females with embryonated (larvated) eggs in the uteri were transferred to one or two Petri dishes (diameter $45 \mathrm{~mm}$ ) (4-8 nematodes per dish) containing water. Their bodies were torn by fine needles and the eggs teased from the uteri. A small amount of detritus, pieces of dry leaves and 5-35 mayfly nymphs were added into each Petri dish. The dishes were covered with a fine nylon cloth fixed with a rubber ring and submerged in a larger glass tank $\left(\begin{array}{lll}40 & 1\end{array}\right)$ with aerated water kept at $20-25^{\circ} \mathrm{C}$. The same method was used in the laboratory of the Institute of Parasitology, ASCR, in České Budějovice, Czech Republic, where the live nematodes were transported by air from Portugal in a vial with physiological saline placed in a thermoflask filled with ice; the water temperature under which the experiment was conducted was $20-22^{\circ} \mathrm{C}$.

The following mayfly nymphs were employed in the experiments: in Portugal: Baetis rhodani (Pictet, 1843), Caenis luctuosa (Burmeister, 1839), Ecdyonurus dispar (Curtis, 1834), Heptagenia sulphurea (Müller, 1776) and Seratella ignita (Poda, 1761); in the Czech Republic: Baetis fuscatus (Linnaeus, 1767), Caenis macrura Stephens, 1835, Ecdyonurus dispar, Habroleptoides modesta (Hagen, 1864), Oligoneuriella rhenana (Imhoff, 1852), Potamanthus luteus (Linnaeus, 1767) and Seratella ignita.

In order to study the nematode larval development, the mayfly nymphs were dissected with the aid of fine needles in a drop of physiological saline on a glass slide and were examined by light microscopy first after 24 hours and then at 1 to 2 days intervals.

One small eel, $A$. anguilla (body length $18 \mathrm{~cm}$ ), which was kept at $10^{\circ} \mathrm{C}$ in the Institute of Parasitology in České Budějovice for five years before the experiment, was force-fed a mayfly nymph presumed to contain infective, 30 days old larvae of $S$. inermis (experimentally infected E. dispar from Portugal). Then the eel was maintained in an aquarium (35 1) at water temperature of $20-22^{\circ} \mathrm{C}$, fed with commercially supplied frozen chironomid larvae, and examined 28 days post infection (p.i.).

The nematode larvae obtained from mayfly nymphs and eels (both naturally and experimentally infected) were fixed in hot $4 \%$ formaldehyde and examined by light microscopy. Very young larvae from mayflies were fixed so that they were first immobilised in a drop of saline on a microscope slide by a short, careful heating of the slide over the flame of a gas burner and a small drop of $4 \%$ formaldehyde was added. For scanning electron microscopy (SEM) examination, some larval nematodes and adults were postfixed in 1\% osmium tetroxide, dehydrated through an ethanol series and acetone, and then subjected to critical point drying. The specimens were coated with gold and examined with a JEOL JSM-6300 scanning electron microscope at an accelerating voltage of 15 $\mathrm{kV}$. All measurements are in micrometres $(\mu \mathrm{m})$ unless otherwise stated.

\section{RESULTS}

\section{Experimental infections}

Experimental infection of mayfly nymphs. Of the mayfly species used in the experiments, Caenis macrura, Ecdyonurus dispar, Heptagenia sulphurea, Potamanthus luteus and Seratella ignita were successfully infected with $S$. inermis.

The eggs of $S$. inermis contain a formed first-stage larva that hatches in the digestive tract of mayfly nymphs. After entering the digestive tract, the first-stage larvae penetrate the intestinal wall by means of a minute cephalic tooth and reach the body cavity of the mayflies. There the larvae moult twice to attain the third stage. The first moult was found to occur 4 days p.i. and the second moult 6-7 days p.i. Fully developed third-stage larvae are located in the abdomen of the intermediate host, occasionally also in the thorax; in heavily infected mayflies also in the head and legs, where they move freely. Usually only the anterior parts of the body of these larvae are spirally coiled (Figs. 1B, 3A), but some larvae were seen entirely coiled. Encapsulated larvae were never detected. No more moults were observed until the end of the experiment (30 days p.i.). Most nymphs in the experiments became infected and the intensity of infection at the beginning of the experiments ranged from 7 to 81 nematode larvae per mayfly; however, many nymphs did not survive the infection and the rate of mortality of mayfly nymphs was very high (about 70\%). All nymphs of Habroleptoides modesta and Ecdyonurus dispar from the Czech Republic died during the experiment. The maximum number of the nematode infective larvae $\left(\mathrm{L}_{3}\right)$ in one mayfly nymph was found to be 70 .

Experimental infection of eel. The experimentally infected eel was examined 28 days p.i. One fourth-stage larva of S. inermis was found attached to the mucosa of the intestine.

\section{Description of developmental stages of $S$. inermis}

Egg (Fig. 1A): The eggs are oval, thick-walled, lightcoloured, with a mostly smooth surface. Larvigerous mature eggs from uterus (Fig. 1A) are 45-54 long and 25-33 wide, and are provided with denticulate polar caps. The size of immature eggs (still without larvae) is 41-50 $\times 17-25$ and their polar caps are rather indistinct.

First-stage larva (Fig. 2A, B): The body of the larvae obtained from mayfly nymphs 2 days p.i. $(n=7)$ (Fig. 2A) is fine and thin, light-coloured, 210-219 long 


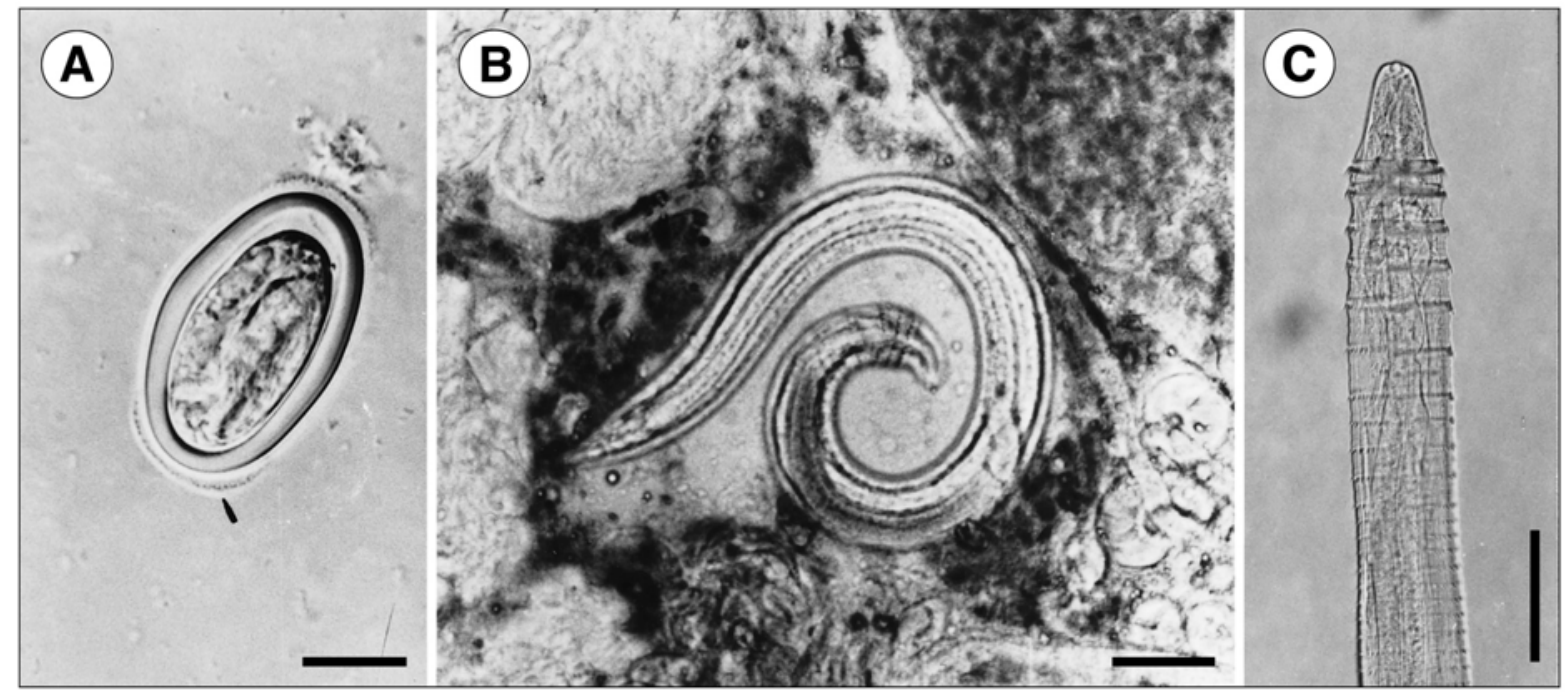

Fig. 1. Spinitectus inermis (Zeder, 1800), developmental stages. A - larvated egg with denticulate polar caps (arrowhead) (fresh mount); $\mathbf{B}$ - third-stage larva in broken body of ephemeropteran nymph (fresh mount); $\mathbf{C}$ - anterior end of fourth-stage larva from intestine of experimentally infected eel. Scale bars: $A=10 \mu \mathrm{m} ; \mathrm{B}=100 \mu \mathrm{m} ; \mathrm{C}=200 \mu \mathrm{m}$.

and 9-12 wide. The cuticle is very thin and smooth. The anterior end is provided with a minute sclerotised tooth. The mouth tube is indistinct, being covered by a mass of cells. The internal organisation of the body is not well visible. The undivided oesophagus is $90-96$ long, being encircled by a nerve ring at its approximately one third. The excretory cell is large, opening through a thin canal approximately in the middle of the oesophageal part of body. The rectum is surrounded by distinct unicellular rectal glands. The genital primordium is near the posterior end of the intestine. The tail is narrow, conical, 36-45 long.

Some larvae (about 20\%) $(n=4)$ from mayflies 4 days p.i. (Fig. 2B) become plump, their bodies are shorter (186-210) and markedly wide (18-24). The oesophagus remains undivided and shorter (66-75). The nerve ring is about 36 from the anterior extremity. Tail remains sharply pointed, 48-60 long. The larvae become less motile and in some of them a loosening of the old cuticle is visible, showing that they start the first moult (Fig. 2C).

Second-stage larva (Fig. 2C): The first moult occurs 4 days p.i. in most advanced larvae. The second-stage larvae remain inside the old cuticle for some time and they considerably grow. Apparently, the next (second) moult starts soon after the first one.

Third-stage (infective) larva (Figs. 1B, 2D-H, 3A$\mathrm{D})$ : The most advanced larvae undergo their second moult on days 6-7. Moulting $\mathrm{L}_{3}$ (Fig. 2D) $(\mathrm{n}=10)$ are already 300-400 long and 30-36 wide. They are still inside the shed cuticle of the second stage. The vestibule is not completely sclerotised, but is visible, 18-24 long. The oesophagus of these larvae is still not distinctly divided into muscular and glandular parts and its posterior end is somewhat bulbously expanded; the entire oesophagus is 93-102 long. Spines become visible beneath the old cuticle near the cephalic region. The nerve ring and the excretory pore are 36-42 and 45-60, respectively, from the anterior extremity. The genital primordium remains ventrally near the posterior end of the intestine. The tail is 27-40 long and the tail tip is now distinctly rounded. Most larvae obtained 11 days p.i. were the third-stage larvae already free of the old cuticle of the previous stage.

The third-stage larvae from mayflies until 30 days p.i. $(\mathrm{n}=10)$ (measurements of one larva from a naturally infected eel in brackets) (Figs. 1B, 2E-H, 3A-D) are 600-1,240 [1,420] long, maximum width 36-65 [75], covered by rings of cuticular spines. The cephalic end (Figs. 2F, 3B, D) is rounded, with two lateral pseudolabia; the margin of the oral aperture is supported by four small sclerotised plates, the two ventral and the two dorsal connected in such a way that they form a Vshaped structure (Figs. 2F, 3D); four small cephalic papillae and a pair of lateral amphids are present. Anterior rings of cuticular spines are divided into two semicircles, each composed of about 9-12 [18-24 per ring] spines (Fig. 3B). Six anteriormost rings are formed by spines 9 long, spines of more posterior rings are distinctly smaller, about 3 long. Posterior rings are often incomplete (Figs. 2E, 3A). The number of rings on the whole body is $38-46$ (Fig. 2E). The length of the vestibule including the prostom, the muscular oesophagus and the glandular oesophagus are 42-52 [55], 75-113 [135] and 165-315 [450], respectively, long; the prostom is 8-12 [12] long and 6-9 [6] wide. 


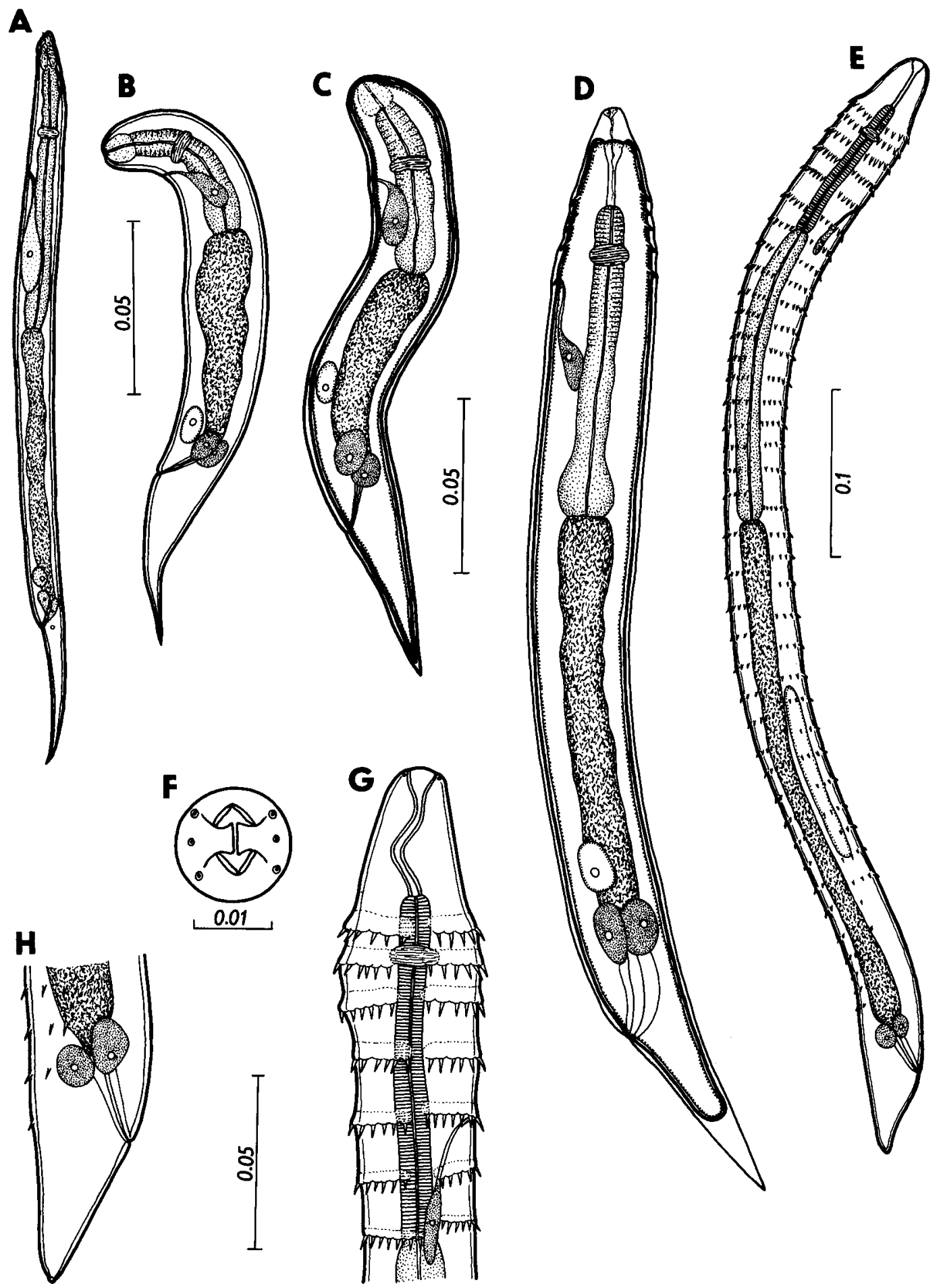

Fig. 2. Spinitectus inermis (Zeder, 1800), larvae from experimentally infected intermediate hosts (ephemeropteran nymphs). $\mathbf{A}$ - first-stage larva 2 days p.i.; $\mathbf{B}$ - advanced first-stage larva 4 days p.i.; $\mathbf{C}$ - second-stage larva undergoing first moult 4 days p.i.; D - young third-stage larva undergoing moult 7 days p.i.; $\mathbf{E}$ - fully developed third-stage larva 30 days p.i.; $\mathbf{F}$ - cephalic end of third-stage larva, apical view (reconstructed from scanning electron micrograph); $\mathbf{G}$ - cephalic end of third-stage larva, lateral view; $\mathbf{H}$ - tail of third-stage larva, lateral view. Scale bars in $\mathrm{mm}$. 

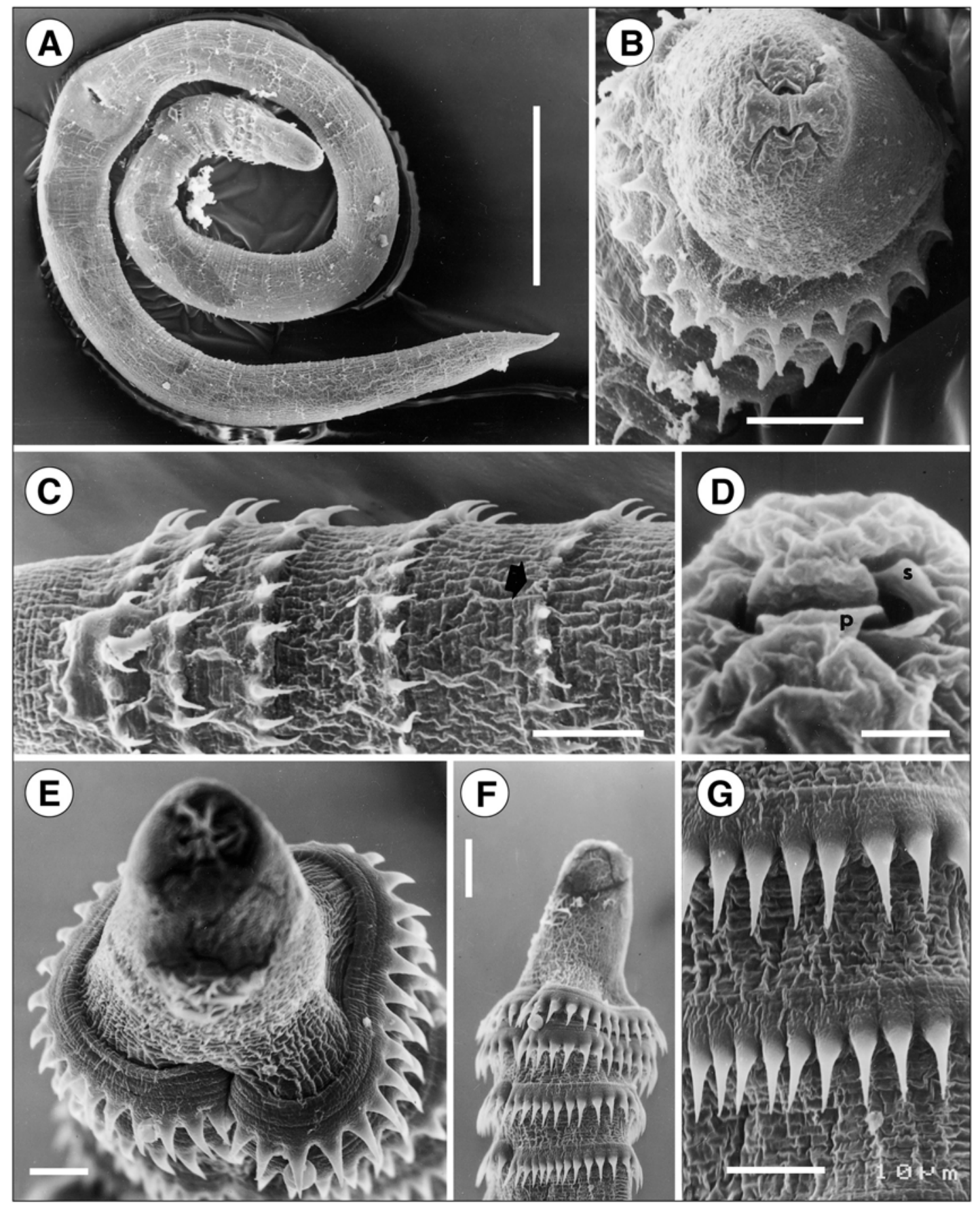

Fig. 3. Spinitectus inermis (Zeder, 1800), scanning electron micrographs of larvae. A-D - third-stage larva from experimentally infected ephemeropteran nymph 30 days p.i. (A - general view; $\mathbf{B}$ - cephalic end, apical view; $\mathbf{C}$ - subventral view of anterior part of body showing excretory pore (arrow) at level of fifth ring of spines; D - mouth, dorsoventral view). E-G - female fourthstage larva from experimentally infected eel 28 days p.i. ( $\mathbf{E}$ - cephalic end, subapical view focused on cuticular spines, showing subdivision of anterior ring into two hemicircles; $\mathbf{F}$ - cephalic end, dorsoventral view; $\mathbf{G}$ - detail of spines in anterior rings). $\mathrm{p}-$ pseudolabium; s - sclerotised plate. Scale bars: $\mathrm{A}=100 \mu \mathrm{m} ; \mathrm{B}, \mathrm{C}, \mathrm{E}, \mathrm{G}=10 \mu \mathrm{m} ; \mathrm{D}=2 \mu \mathrm{m} ; \mathrm{F}=20 \mu \mathrm{m}$.

The nerve ring and the excretory pore are 61-88 [88] and 93-135 [135], respectively, from the anterior extremity; the latter opening at the level of the fifth ring of cuticular spines (Figs. 2G, 3C). The intestine is narrow, light-coloured. Three large unicellular rectal glands are present. The genital primordium is elongate, 60-123 long, situated near the mid-length of the intestine, 183-255 from the posterior extremity. The tail is conical, relatively short, 48-63 [56] long, with a minute terminal cuticular knob (Fig. 2H). 


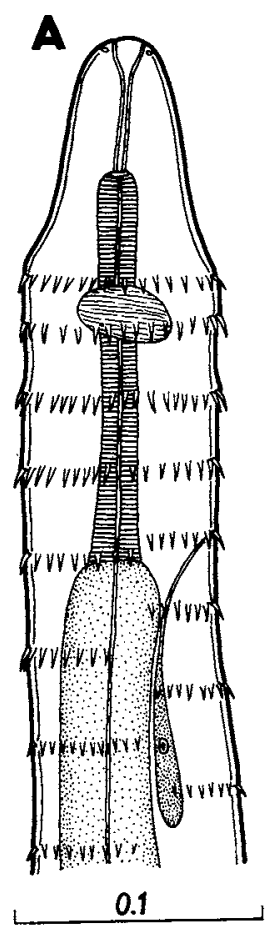

B

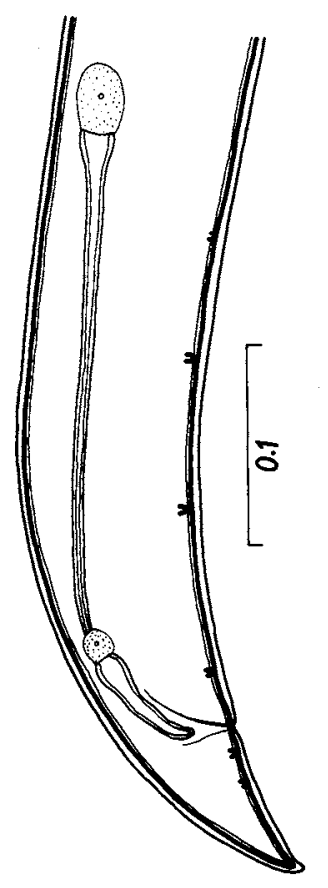

$\mathbf{E}$

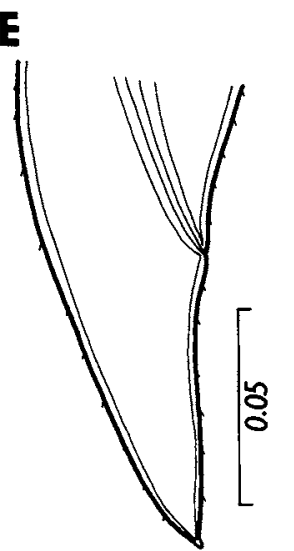

C
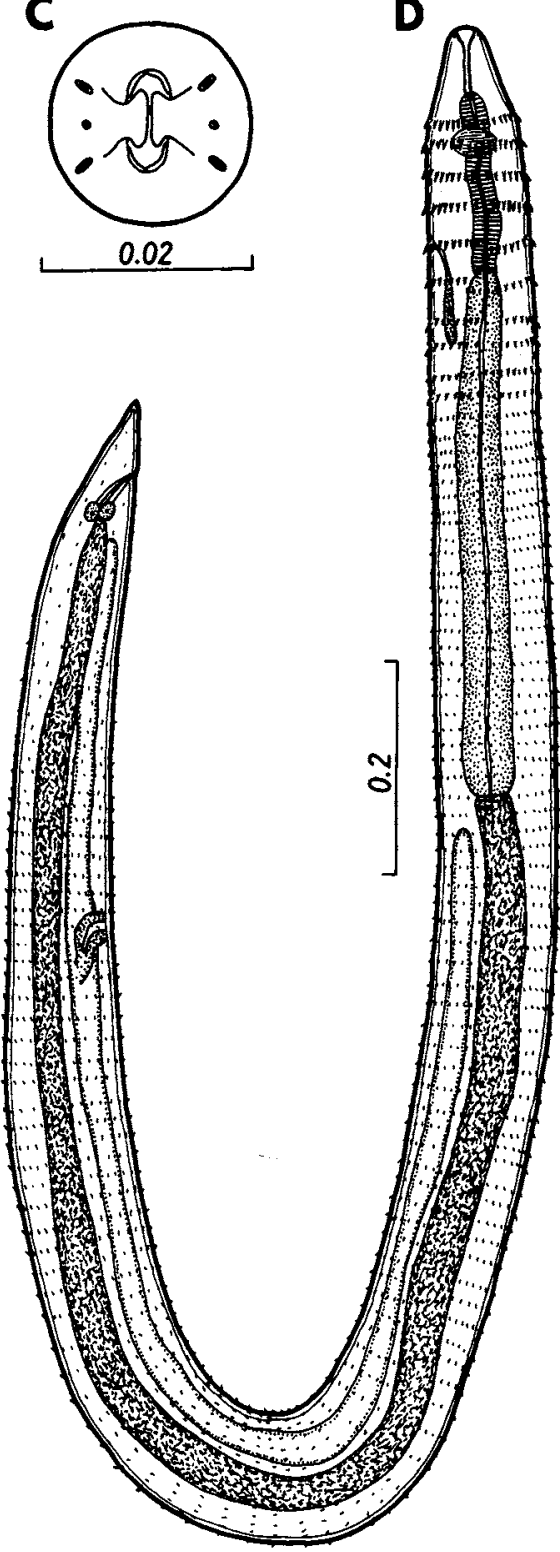

Fig. 4. Spinitectus inermis (Zeder, 1800), fourth-stage larvae from definitive host (eel). A-cephalic end, lateral view; $\mathbf{B}$ - advanced male larva starting last (fourth) moult (note developing spicules and caudal papillae); $\mathbf{C}$ - cephalic end, apical view (reconstructed from scanning electron micrograph); D - female larva, general view (note developing vulva and vagina); $\mathbf{E}-$ tail, lateral view; F - tail of male larva starting last (fourth) moult. (A-C, E, F - larvae from naturally infected eels; D - larva from experimentally infected eel 28 days p.i.). Scale bars in $\mathrm{mm}$.

Fourth-stage larva (Figs. 1C, 3E-G, 4A-F): Fourthstage larvae from naturally infected eels $(\mathrm{n}=3)$ (measurements of one larva from an experimental eel 28 days p.i. in brackets) are $1.880-3.280 \mathrm{~mm}$ [2.747 mm] long, maximum width 96-138 [122]. The structure of the cephalic end (Fig. 4C) is similar to that of $\mathrm{L}_{3}$, differing somewhat in the shape of the structure formed by the two ventral and the two dorsal plates (U-shaped) and in the shape (elongate) of cephalic papillae. Six anteriormost rings of spines (divided into two semicircles) have distinctly larger (length 6-9) spines than the following rings (3) (Figs. 3E-G, 4A, D). The first ring is formed by approximately 36-38 spines (Fig. $3 \mathrm{E})$. Posterior rings of spines are often incomplete; spines are also present on the tail. The number of cuticular rings is always more than 100 [110] (Fig. 4D). The length of the vestibule including the prostom, the muscular oesophagus and the glandular oesophagus is 57-75 [72], 140-195 [171] and 515-825 [600], respectively; the prostom is $12-16$ [12] long and 10-15 [12] wide. The nerve ring and the excretory pore are 100-129 [126] and 200-204 [not found], respectively, 


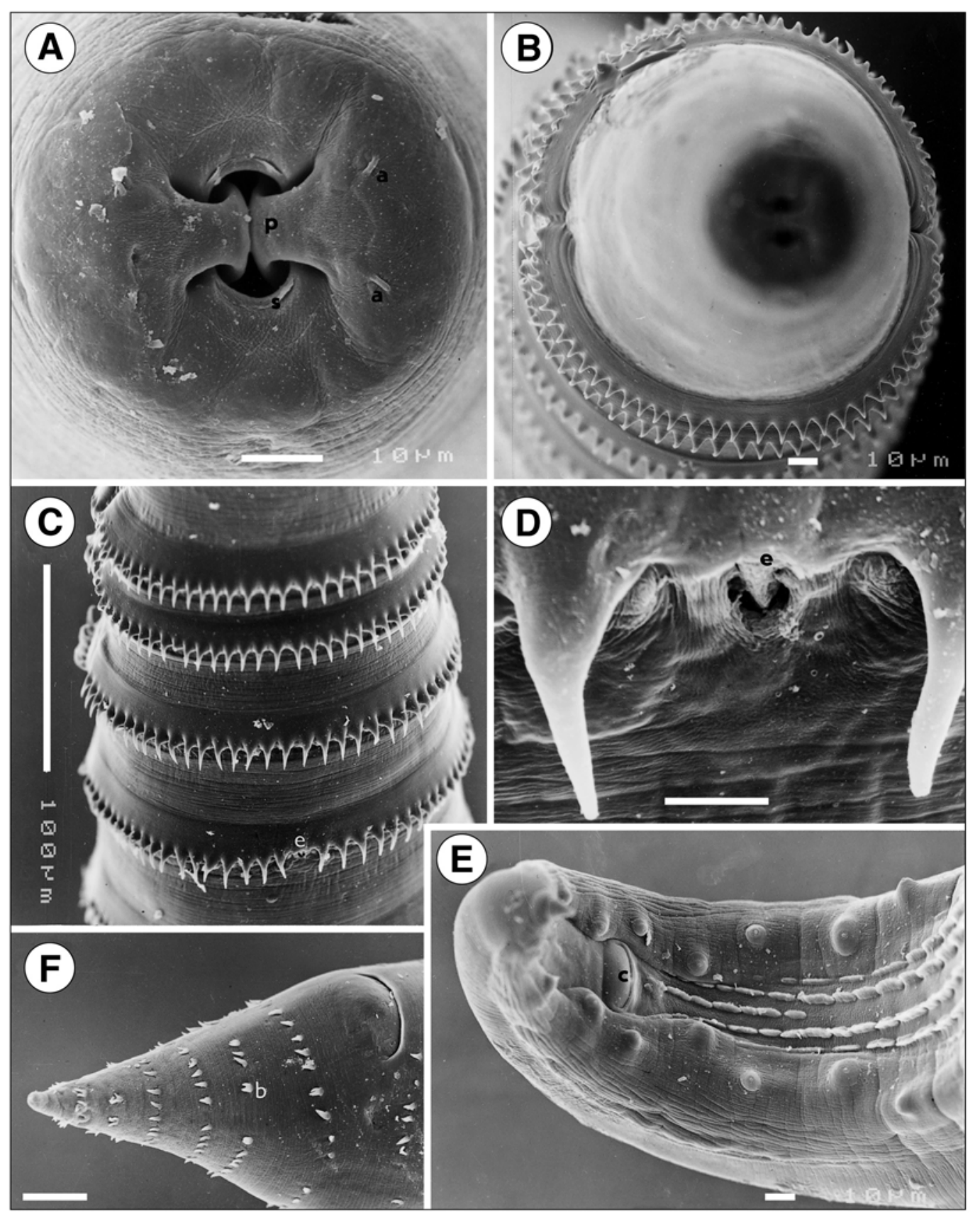

Fig. 5. Spinitectus inermis (Zeder, 1800), scanning electron micrographs of adults from naturally infected eels in Portugal. A - cephalic end, apical view; B - cephalic end, apical view (focused on cuticular spines) showing that rings are formed by two hemicircles; C - anterior part of body, ventral view, showing excretory pore at level of fourth ring of spines; $\mathbf{D}$ - region of excretory pore, ventral view; $\mathbf{E}$ - tail of male with distinct arrangement of caudal papillae, ventral view; $\mathbf{F}$ - tail of gravid female, subventral view (note that some cuticular spines are doubled). $\mathrm{a}$ - cephalic papilla; $\mathrm{b}$ - doubled cuticular spine; $\mathrm{c}-\mathrm{cloacal}$ opening; e- excretory pore; $\mathrm{p}$ - pseudolabium; $\mathrm{s}$ - sclerotised plate. Scale bars: $\mathrm{A}, \mathrm{B}, \mathrm{E}=10 \mu \mathrm{m} ; \mathrm{C}=100 \mu \mathrm{m} ; \mathrm{D}=5 \mu \mathrm{m} ; \mathrm{F}=20 \mu \mathrm{m}$.

the latter opening just anterior to the fifth cuticular ring. The intestine is narrow. The genital primordium is tubular, very long, occupying most length of the body posterior to the oesophagus; female larvae are with a developing vagina and vulva (still covered by the cuticle) situated 233-350 [560] from the posterior extremity; in the larger male larva (2.992 mm long), already developing spicules (363 and 63 long) are present and caudal papillae are visible beneath the cuticle. The tail is conical, 65-93 [75] long, with a small mucron on tip (Fig. 4E). 


\section{DISCUSSION}

In general, the development of Spinitectus inermis is similar to that of other representatives of the family Cystidicolidae.

The morphogenesis of $S$. inermis larvae in the mayfly intermediate host is very similar to that found by Keppner (1975) in S. micracanthus; however, in contrast to $S$. inermis, the larval development of $S$. micracanthus was found to be distinctly slower (first and second moults observed 6-10 and 19 days p.i., respectively, at 21$23^{\circ} \mathrm{C}$ ). The larval morphology of $S$. carolini and $S$. gracilis as described by Jilek and Crites $(1982 \mathrm{a}, \mathrm{b})$ is not well documented; for both species the authors reported the first moult to occur already $18 \mathrm{~h}$ p.i. and the second one 8 days p.i. but, apparently, their observations on individual larval stages are inaccurate (e.g., they report the appearance of cuticular spines in $\mathrm{L}_{1}$ !). In contrast to some other cystidicolids and rhabdochonids which can undergo their third moult already in the arthropod intermediate host, the hitherto experimental results as well as observations from nature indicate that the larval development of Spinitectus spp. in the intermediate host ceases at the third stage; this is confirmed by this study.

The fourth-stage larvae can be easily distinguished from the third-stage larvae by the number of rings of spines on the whole body (less than 50 and more than 100 in the third- and fourth-stage larvae, respectively), number of spines in anterior rings (18-24 and 36-38 per ring in the third- and the fourth-stage larvae, respectively), and the development of sexual organs (undifferentiated in the third stage vs. already differentiated in the fourth stage).

As compared to third-stage larvae, the general morphology of fourth-stage larvae is more similar to that of adults. Their sclerotised plates in the mouth have almost the same shape as in adults and the same concerns the elongate shape of cephalic papillae (see Fig. 5A). However, the fourth-stage larvae differ from adults in the position of the excretory pore, this being just anterior to the fifth ring of cuticular spines in the former and at the level of the fourth ring in the latter (Fig. 5C, D). The position of the excretory pore in adult Spinitectus spp. is considered one of the most stable and taxonomically very important features (Moravec 1979) and, therefore, a distinction between adults and conspecific fourth-stage larvae is a prerequisite to use this criterion. It is obvious from this study that the position of the excretory pore in $S$. inermis moves from the level of the fifth ring of cuticular spines to that of the fourth ring during the development from the thirdstage larva to the adult.

Adults differ from fourth-stage larvae also in having distinctly more (56-83) spines in the first ring (Fig. 5B). The tail of female fourth-stage larvae bears cuticular spines as that of adult females, but some spines on the latter may be double (Fig. 5F). It was observed that the male fourth-stage larva starting the last (fourth) moult possessed already sclerotised spicules and caudal papillae with approximately the same arrangement as in the adult male (Fig. 5E).

Data concerning the rate of development in the definitive host are rather scarce in Spinitectus spp. Gustafson (1939) reports that he obtained young adults of $S$. gracilis from experimentally infected fish 3 days p.i., but this is evidently incorrect, because such a short period is not enough to allow the parasites to grow into adults in the cold-blooded vertebrates, as already pointed out by Hasegawa and Otsuru (1977). According to Jilek and Crites (1982b), larvae of $S$. gracilis in the fish definitive host (at $20^{\circ} \mathrm{C}$ ) undergo the third moult 3 days p.i. and the fourth moult 15 days p.i., and the whole prepatent period is 24 days. Similar data are reported by Jilek and Crites (1982a) for S. carolini, where, at the same water temperature $\left(20^{\circ} \mathrm{C}\right)$, the third and the fourth larval moults in the definitive host take place 2 and 14 days p.i., respectively, and the prepatent period is 21 days.

Keppner (1975) observed in S. micracanthus only one moult of larvae (considered to be the last moult) in the fish host 16 days p.i., but the morphological differences (mainly in the character of the cuticular spination) that he observed between the pre-moult and the post-moult larvae are similar to those found in the present study between the third- and the fourth-stage larvae in S. inermis; therefore, it is highly probable that, in fact, Keppner observed the third moult. Hasegawa and Otsuru (1977) correctly remark that the micrograph (fig. 22) by Keppner (1975), showing allegedly the posterior end of the female, concerns in fact the fourthstage larva. This suggests that two moults occur in the definitive host also in S. micracanthus. Keppner (1975) observed fully mature males and females with immature eggs of $S$. micracanthus on days 26 and 36 after infection, respectively. Hasegawa and Otsuru (1977) report the prepatent period of $S$. ranae in different experimentally infected anuran species to last 14-45 days. Taking all these data into account, as also the record of the fourth-stage larva of $S$. inermis in an experimental eel 28 days p.i., the prepatent period of $S$. inermis can be estimated to last at least two months.

Moravec (1994) assumed mayfly nymphs or the freshwater isopod Asellus aquaticus L. to be possible intermediate hosts of $S$. inermis. In the present study, only mayfly nymphs were employed as intermediate hosts of $S$. inermis, because they constitute one of the most important prey items of the eel population studied. Nevertheless, it must be emphasised that also other insect larvae could be intermediate hosts of $S$. inermis. According to Moravec (1994), aquatic insects, mainly mayflies, serve as intermediate hosts of some freshwater representatives of the family Cystidicolidae, and Jilek and Crites (1981) showed that aquatic insect larvae of several different orders were suitable intermediate hosts 
of two important Spinitectus species of North American freshwater fishes. Infected mayflies are probably the main source of $S$. inermis infection for eels, although there may be, apparently, some paratenic hosts (prey fishes) involved in the life cycle of this nematode.

Acknowledgements. We are grateful to Tomáš Soldán and Milan Putz of the Institute of Entomology, ASCR, in České Budějovice, who kindly identified the mayflies. Thanks are also due to the staff of the Laboratory of Electron Microscopy of the Institute of Parasitology, ASCR, in České Budějovice for their technical assistance and to Irena Husáková of the Laboratory of Helminthology of the same institute for her help with the preparation of illustrations. The study was supported by CIIMAR - Interdisciplinary Centre of Marine and Environmental Research in Portugal and by grant No. A6022901 from the Grant Agency of the Academy of Sciences of the Czech Republic.

\section{REFERENCES}

ALI M.M. 1980: On a larva of a spiruroid nematode of fish Acta Parasitol. Pol. 27: 387-389.

BOOMKER J. 1993: Parasites of South African freshwater fish. V. Description of two new species of the genus Spinitectus Fourment, 1883 (Nematoda: Cystidicolidae). Onderstepoort J. Vet. Res. 60: 139-145.

GUSTAFSON P.V. 1939: Life cycle studies on Spinitectus gracilis and Rhabdochona sp. (Nematoda: Thelaziidae). J. Parasitol. 25 (Suppl.): 12-13.

HASEGAWA H. 1978: Larval nematodes of the superfamily Spiruroidea. A description, identification and examination of their pathogenicity. Acta Med. Biol. 26: 79-116.

HASEGAWA H., OTSURU M. 1977: Life cycle of a frog nematode, Spinitectus ranae Morishita, 1926 (Cystidicolidae). Jpn. J. Parasitol. 26: 336-344.

JILEK R., CRITES J.L. 1980: Pathological implications of Spinitectus carolini (Spirurida: Nematoda) infections to survival of mayflies and dragonflies. J. Invertebr. Pathol. 36: $144-146$

JILEK R., CRITES J.L. 1981: Observations on the lack of specificity of Spinitectus carolini and Spinitectus gracilis (Spirurida: Nematoda) for their intermediate hosts. Can. J. Zool. 59: 476-477.

JILEK R., CRITES J.L. 1982a: The life cycle and development of Spinitectus carolini Holl, 1928 (Nematoda: Spirurida). Am. Midl. Nat. 107: 100-106.
JILEK R., CRITES J.L. 1982b: The life cycle and development of Spinitectus gracilis (Nematoda: Spirurida). Trans. Am. Microsc. Soc. 101: 75-83.

JOHNSON S. 1966: On a Spinitectus larva (Spiruroidea: Nematoda) from a shrimp (Crustacea) in India. Indian J. Helminthol. 18: 49-52.

KEPPNER E.J. 1975: Life cycle of Spinitectus micracanthus Christian, 1972 (Nematoda: Rhabdochonidae) from the bluegill, Lepomis macrochirus Rafinesque, in Missouri with a note on Spinitectus gracilis Ward and Magath, 1917. Am. Midl. Nat. 93: 411-423.

MORAVEC F. 1979: Redescription of the nematode Spinitectus inermis parasitic in eels, Anguilla anguilla, of Europe. Acta Soc. Zool. Bohemoslov. 43: 35-42.

MORAVEC F. 1994: Nematodes of Freshwater Fishes of Europe. Academia and Kluwer Acad. Publishers, Praha and Dordrecht, Boston, London, $473 \mathrm{pp}$.

OTSURU M., SHIRAKI T., KENMOTSU M., KAKIZAKI Y. 1974: Some cases of larval or adult nematode migrations in the human tissue. Jpn. J. Parasitol. 23: 106-115. (In Japanese.)

YAMAGUTI S., NISHIMURA H. 1944: One nematode and two trematode larvae from Caridina denticulata de Haan. Hukuoka Acta Med. 37: 411. (In Japanese.) 